\title{
Relative effectiveness of additive pain interventions during vaccination in infants
}

\author{
Anna Taddio PhD RPh, Rebecca Pillai Riddell PhD RPsych, Moshe Ipp MD, Steven Moss MD, \\ Stephen Baker MD, Jonathan Tolkin MD, Dave Malini MD, Sharmeen Feerasta MD, Preeya Govan MD, \\ Emma Fletcher BA, Horace Wong BSc, Caitlin McNair BA, Priyanjali Mithal BA, Derek Stephens MSc
}

— Cite as: CMAJ 2017 February 13;189:E227-34. doi: 10.1503/cmaj.160542

Infographic available at www.cmaj.ca/lookup/suppl/doi:10.1503/cmaj.160542 /-/DC1

\begin{abstract}
BACKGROUND: Vaccine injections can cause acute pain and distress in infants, which can contribute to dissatisfaction with the vaccination experience and vaccine hesitancy. We sought to compare the effectiveness of additive pain interventions administered consistently during vaccine injections in the first year of life.
\end{abstract}

METHODS: We conducted a multicentre, longitudinal, double-blind, add-on, randomized controlled trial. Healthy infants were randomly assigned to 1 of 4 levels of pain management for all vaccine injections at 2, 4, 6 and 12 months: (i) placebo control; (ii) parent-directed video education about infant soothing; (iii) the video plus sucrose administered orally or (iv) the video plus sucrose plus liposomal lidocaine applied topically. All infants benefit from injection techniques that minimize pain. We used a doubledummy design; hence all parents watched a video (active psychological intervention or placebo) and all infants received oral solution (sucrose or placebo) and topical cream (lidocaine or placebo). We assessed infant distress during 3 phases - preinjection (baseline), vaccine injection (needle), and 1 minute postinjection (recovery) using the Modified Behavioural Pain Scale (range 0-10). We compared scores between groups and across infant ages using a mixed-model repeated-measures analysis.

RESULTS: A total of 352 infants participated in the study, from Jan. 17, 2012, to Feb. 2, 2016. Demographics did not differ among intervention groups $(p>0.05)$. Baseline pain scores did not differ among intervention groups $(p=0.4)$, but did differ across ages $(p<0.001)$. Needle pain scores differed among groups $(p=0.003)$ and across ages $(p<0.001)$. The mean $( \pm$ standard deviation) needle score was 6.3 $( \pm 0.8)$ in the video-sucrose-lidocaine group compared with $6.7( \pm 0.8)$ in each of the other groups. There were no other between-group differences. Recovery scores did not differ among groups ( $p=$ $0.98)$, but did differ across ages $(p<0.001)$.

INTERPRETATION: Only liposomal lidocaine provided consistent analgesia within an additive pain intervention regimen during vaccinations in infants. Trial registration: ClinicalTrials.gov, no. NCT01503060
V accine injections are associated with acute distress in infants, ${ }^{1,2}$ which can contribute to dissatisfaction with the vaccination experience and vaccine hesitancy. ${ }^{3-5}$ Mitigating pain is therefore clinically relevant and important. National clinical practice guidelines promote a variety of pain mitigation interventions, ${ }^{6,7}$ and these are incorporated in the Canadian Immunization Guide (www.phac-aspc.gc.ca/publicat/ cig-gci/p01-07-eng.php). Surveys of pain management practices, however, show low uptake rates, particularly for interventions that require additional time and resources. ${ }^{8-10}$

At present, there is a gap in primary research regarding the pain intervention regimens that achieve maximal analgesia. Specifically, there is a dearth of data regarding the relative effects of combined interventions and their effectiveness over time. This prevents clinicians from knowing how to prioritize the interventions that are available. The present study was undertaken to address this knowledge gap. The objective was to compare the relative effectiveness of 3 levels of pain interventions with a placebo control on infant distress levels over time during routine vaccinations. The order of adding on interventions considered complexity of their implementation in clinical practice. We hypothesized that increasing levels of pain management would lead to increasing pain relief.

\section{Methods}

We conducted a multicentre, longitudinal, double-blind, doubledummy, add-on, randomized controlled trial. Healthy infants receiving vaccinations in 3 pediatric outpatient clinics, including 7 physician practices in Toronto were eligible. We excluded infants born before 36 weeks' gestation, infants who had stayed in hospital outside of postnatal care, and infants who were allergic to amide 
anesthetics or vaccines and for whom mothers planned to use topical anesthetics, sucrose or breast feeding during vaccinations.

Infants were randomly assigned to 1 of 4 pain-relieving regimens for all vaccine injections in their first year of life: (i) placebo control; (ii) parent-directed video education about infant soothing; (iii) the video plus orally administered sucrose; and (iv) the video plus sucrose plus topically applied lidocaine. A double-dummy design was used; hence all parents watched a video (active psychological intervention or placebo), all infants received oral solution ( $24 \%$ sucrose in water or placebo), and all infants received topical cream (active lidocaine $4 \%$ or placebo) before vaccinations. The active video instructed parents in a mnemonic $(A B C D$, whereby $A=$ assess distress, $B=$ belly breathing, $C=$ cuddle, $D=$ distract) based on a systematic review ${ }^{11}$ and a cohort study; ${ }^{12-14}$ the placebo video provided general (nondirective) information only (Box 1). Preliminary effectiveness of the video was shown in a pilot trial. ${ }^{15}$

Using a computer random number generator, an off-site pharmacist constructed a randomization table in block sizes of 8 with a 1:1:1:1 ratio. The table was maintained in a secure location in the pharmacy inaccessible to researchers. Sequentially numbered study kits with sufficient supplies for 2-, 4-, 6- and 12-month vaccinations were dispensed to the sites. Each kit contained study cream (liposomal lidocaine $4 \%$ or placebo), study solution (sucrose $24 \%$ or placebo), and one digital video disc (5-min active or 5-min placebo). The pharmacist was not involved in any other aspect of the trial.

Upon arrival of the infant at the clinic for a vaccination appointment, $1 \mathrm{~g}$ of study cream was applied to the injection site (upper outer aspect of the thigh for 1 scheduled injection or thighs for more than 1 injection in infants aged $<1 \mathrm{yr}$; the deltoid for infants aged $\geq 1 \mathrm{yr})^{6}$ and covered with an occlusive dressing or plastic wrap. Parents then privately viewed the study video with a portable disc player. After the minimum requisite cream application time (20 min) had elapsed and the attending physician was available for vaccine administration, the cream was removed. Removal of the occlusive dressing involved stretching one corner horizontally while securing the opposite corner so that it lifted off the skin without causing discomfort. Two millilitres of study solution was administered orally 1-2 minutes before vaccine injection.

At 2 and 4 months, infants received diphtheria, tetanus, acellular pertussis, inactivated polio virus, Hemophilus influenzae type B vaccine and pneumococcal conjugate vaccine. Six-month-old infants received diphtheria, tetanus, acellular pertussis, inactivated polio virus and Hemophilus influenzae type B. At 12 months, one of meningococcal group $\mathrm{C}$ conjugate and measles-mumps-rubella, or meningococcal group $\mathrm{C}$ conjugate and pneumococcal conjugate, or meningococcal group $\mathrm{C}$ conjugate, measles-mumpsrubella and pneumococcal conjugate were administered. A 25- to

Box 1: Content of active and placebo educational videos

\section{Active* $^{*}$}

\section{A: Assess your own stress}

- Take a few belly breathes while holding your infant, and the baby will feel the rhythmic breathing, which is calming

\section{B: Belly breathing}

- Take a slow deep breath through your nose for 3 seconds, expanding your belly and not your chest

- Then breathe out through your mouth for 3 seconds; each time, count 3 seconds

- Repeat this 3 times while cuddling your baby

\section{C: Cuddle and calmly talk to your baby}

- Babies should always be held closely before, during and after the needle

- If the needle is going in the your infant's arm (or thigh), hold the arm (or thigh) firmly but gently, so the baby won't move it

- Calmly talk to your child after the needle

- Let your child know you're there for them, bring them closer, and talk about anything but the needle or pain

- Many parents find it easiest to talk about what they will do when they leave the office

- The baby may not understand the words, but they understand your tone

\section{D: Distract your baby}

- Distract your baby and take their attention away from the pain

- Distraction can only occur once the infant is ready to be distracted; this is typically between 20 seconds and 1 minute after the needle

- Trying to distract the child when they're not ready to be distracted can cause more distress

- If the infant isn't ready to be distracted, return to cuddling for a little longer

\section{Placebo*}

\section{A: Act in your child's best interest}

- Make decisions that you think are best based on your child

\section{B: Be aware that needles are distressing}

- Needles are distressing for adults, so of course they are distressing for your child

\section{C: Carry out what you think is best for your infant}

\section{D: Do your best to help your child}

*Both videos included introductory comments about the epidemiology of vaccination pain. The placebo video included injection techniques used by health care professionals to reduce pain (i.e., order and speed of injections). 
27-gauge, 5/8- to 1-inch needle was used; for intramuscular injections, there was no prior aspiration. ${ }^{6}$ Multiple injections were separated by 1 minute and more painful vaccines were given last. ${ }^{6}$ The procedure was videotaped using a hand-held digital camera. An orally administered rotavirus vaccine was given to 2 - and 4-monthold infants after the injectable vaccines. Parents did not feed infants during vaccination; however, they could do so before and after the procedure was over.

The primary outcome was infant distress assessed using a continuous scale validated for infant vaccination pain, the Modified Behavioural Pain Scale. ${ }^{16}$ This tool incorporates 3 domains of infant behaviour (facial grimacing, crying and body movements) that are individually assessed in a 15-second interval and summed together for an overall score from 0 (no pain) to 10 (maximum pain). An absolute change of 0.6 points has been used to support practice change. ${ }^{17}$

The Modified Behavioural Pain Scale was coded from videotapes by research assistants blinded to group allocation during 3 procedure phases: preinjection (baseline), during injection (nee- dle) and 1 minute after injection (recovery). ${ }^{18}$ The mean needle pain score was used at appointments with more than 1 injection. ${ }^{18}$ Reliability was assessed by recoding $20 \%$ of the videos, and the intraclass correlation coefficient was $>0.9(p<0.001)$.

Secondary outcomes of pain included dichotomized Modified Behavioural Pain Scale scores (using a cut-off of 2 for no pain/ pain), cry duration and observer-rated pain (parents, physicians and researchers) during injection. ${ }^{18,19}$ Cry duration, defined as audible vocalization in the presence of facial grimacing, was assessed from the videotapes by the previously mentioned research assistants in the 30 seconds after an injection. Parents and physicians assessed needle pain in real time using a numeric rating scale (range 0-10) and a research assistant in the room rated pain using the Modified Behavioural Pain Scale. Parents reported satisfaction with pain management using a 5-point Likert scale (very dissatisfied, somewhat dissatisfied, neutral, somewhat satisfied, very satisfied). The presence of local skin reactions was assessed after cream removal.

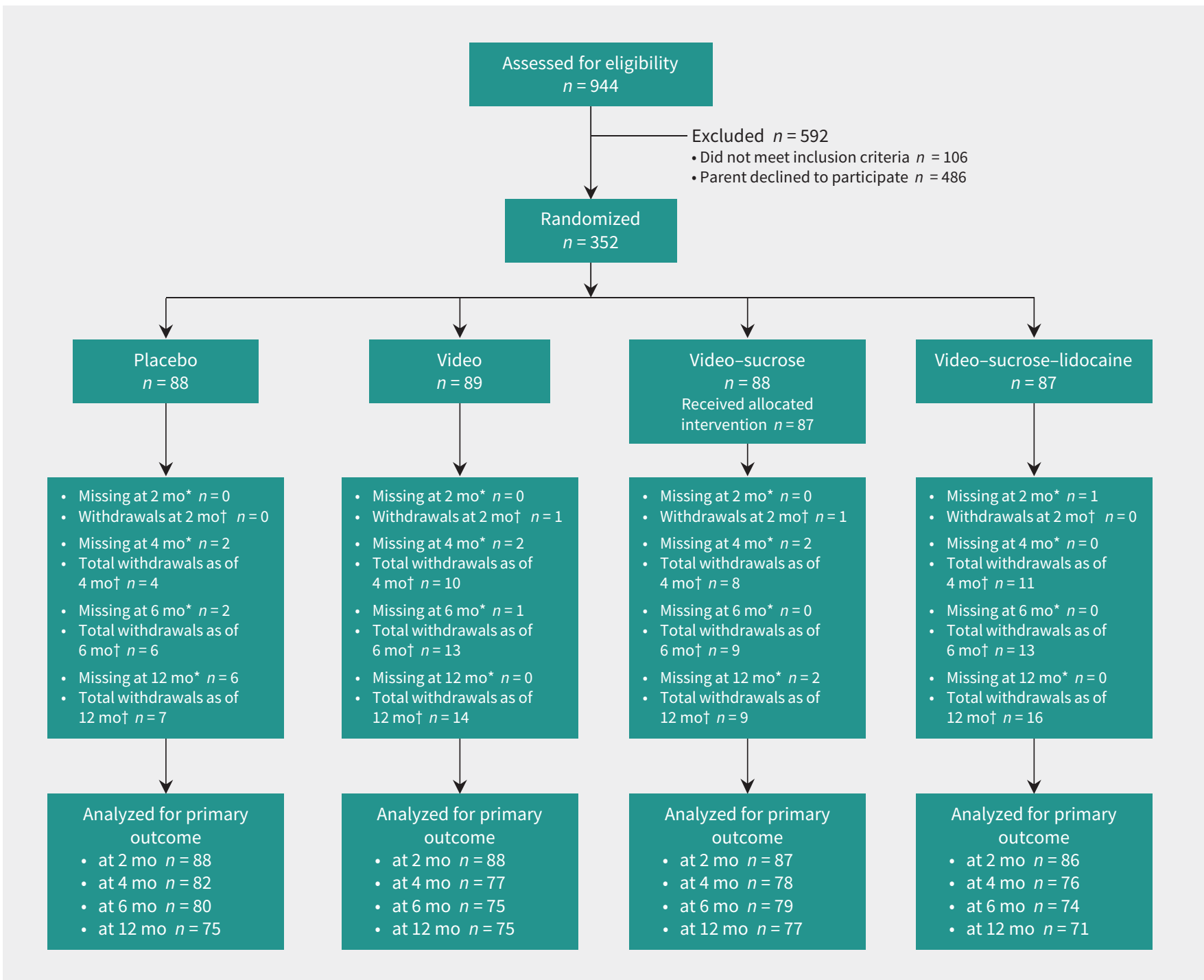

Figure 1: Flow of participants through the study. ${ }^{*}$ Reasons for missing follow-up include appointment missed by study staff or study patient, or videotaping error. †Reasons for withdrawals include intention to use pain interventions, study-specific concerns, moving, time concerns, dislike of videotaping, wanting to see natural response or questioning the effectivness of interventions, stress of vaccinations, meeting exclusion critiera or no reason given. 


\section{Sample size and statistical analysis}

A sample size of 352 (88/group) was calculated to show an effect size of 0.2 (based on between- and within-groups standard deviations of 0.5 and 2.3 , respectively), with $80 \%$ power and $\alpha=2 \%$ (0.05/3 to account for multiple comparisons - baseline, needle and recovery) and accounting for drop outs. ${ }^{20} \mathrm{An}$ effect size of 0.2 was considered important because the pain from vaccine injections is by nature an iatrogenic harm for which interventions should be offered even if there is limited benefit. ${ }^{18}$ The score at each time (i.e., 2, 4, 6, and $12 \mathrm{mo}$ ) was compared among groups with a mixed-model repeated-measures analysis including all the data that were present. Main effects (group and time - differences among groups and infant ages) and interaction effects (group by time - different group effects for different infant ages) were examined. Interaction effects were removed from the model if they were nonsignificant. Mixed-model repeatedmeasures analysis was similarly used for secondary outcomes, including parent and physician numeric rating scale scores, observer Modified Behavioural Pain Scale scores, cry duration and parent satisfaction with pain management. Dichotomized Modified Behavioural Pain Scale scores were compared using a Cochran-Mantel-Hansel test. Demographics were compared using analysis of variance or $\chi^{2}$. The level of significance was set at $p$ less than 0.05 . The primary analysis was performed at the end of the study using an intent-to-treat analysis approach. A post-hoc analysis that incorporated duration of lidocaine application and elapsed time between sucrose administration and injection as covariates in the model was carried out for Modified Behavioural Pain Scale needle scores. Statistical analyses were performed using SAS version 9.4 software.

\section{Ethics approval}

The study was approved by our institutional research ethics boards and parents provided written consent for their infants' participation.

\section{Results}

The study was conducted between Jan. 17, 2012, and Feb. 2, 2016. Of 944 infants who underwent screening, 838 (88.8\%) met the inclusion criteria and $352(42.0 \%)$ of these infants' parents agreed to participate. Nonparticipating infants did not differ from participating infants with respect to distribution of boys ( $53 \% \mathrm{v}$. $54 \%, p=0.8)$. Altogether, 88 infants were randomly assigned to the control group, 89 to the video intervention group, 88 to videosucrose group, and 87 to video-sucrose-lidocaine group. Figure 1

Table 1: Characteristics of participating infants

\begin{tabular}{|c|c|c|c|c|c|}
\hline \multirow[b]{2}{*}{ Characteristic } & \multicolumn{4}{|c|}{ No. $(\%)^{\star}$} & \multirow[b]{2}{*}{$p$ value } \\
\hline & $\begin{array}{l}\text { Placebo control } \\
\quad n=88\end{array}$ & $\begin{array}{l}\text { Video } \\
n=89\end{array}$ & $\begin{array}{c}\text { Video-sucrose } \\
\quad n=88\end{array}$ & $\begin{array}{l}\text { Video-sucrose-lidocaine } \\
\qquad n=87\end{array}$ & \\
\hline \multicolumn{6}{|l|}{ At study entry } \\
\hline Male sex & $46(52)$ & $51(57)$ & $51(58)$ & $44(51)$ & 0.7 \\
\hline White & $49(56)$ & $52(58)$ & $\begin{array}{l}n=87 \\
49(56)\end{array}$ & $51(59)$ & 0.9 \\
\hline No. of siblings & $0.8(0.7)$ & $0.8(0.7)$ & $\begin{array}{c}n=87 \\
0.7(0.7)\end{array}$ & $0.6(0.7)$ & 0.2 \\
\hline At 2 mo & $(n=87)$ & $(n=89)$ & $(n=87)$ & $(n=87)$ & \\
\hline Postnatal age, $d$, mean \pm SD & $64.5 \pm 8.2$ & $63.6 \pm 6.8$ & $65.0 \pm 8.1$ & $64.3 \pm 5.8$ & 0.7 \\
\hline Weight, kg, mean \pm SD & $5.5 \pm 1.0$ & $\begin{array}{c}n=87 \\
5.5 \pm 0.7\end{array}$ & $\begin{array}{c}n=85 \\
5.5 \pm 1.2\end{array}$ & $5.6 \pm 1.3$ & 0.8 \\
\hline At $4 \mathrm{mo}$ & $n=82$ & $n=78$ & $n=79$ & $n=75$ & \\
\hline Postnatal age, $\mathrm{d}$, mean $\pm \mathrm{SD}$ & $128.2 \pm 9.7$ & $126.5 \pm 9.4$ & $129 \pm 11.4$ & $128.3 \pm 11.7$ & 0.5 \\
\hline Weight, kg, mean \pm SD & $\begin{array}{c}n=80 \\
7.0 \pm 1.5\end{array}$ & $\begin{array}{c}n=77 \\
6.9 \pm 0.9\end{array}$ & $\begin{array}{c}n=78 \\
6.8 \pm 1.2\end{array}$ & $6.9 \pm 0.8$ & 0.9 \\
\hline At 6 mo & $n=81$ & $n=75$ & $n=79$ & $n=74$ & \\
\hline Postnatal age, $d$, mean \pm SD & $191.8 \pm 11.2$ & $191.0 \pm 15.8$ & $193.7 \pm 15.1$ & $192.5 \pm 14.3$ & 0.7 \\
\hline Weight, kg, mean \pm SD & $\begin{array}{c}n=80 \\
7.8 \pm 1.2\end{array}$ & $\begin{array}{c}n=74 \\
8.1 \pm 1.9\end{array}$ & $7.7 \pm 1.0$ & $\begin{array}{c}n=73 \\
7.9 \pm 0.9\end{array}$ & 0.2 \\
\hline At $12 \mathrm{mo}$ & $n=76$ & $n=75$ & $n=77$ & $n=71$ & \\
\hline Postnatal age, $d$, mean \pm SD & $378.4 \pm 17.5$ & $376.52 \pm 14.3$ & $374.9 \pm 12.8$ & $378.9 \pm 31.2$ & 0.6 \\
\hline Weight, kg, mean \pm SD & $9.5 \pm 1.4$ & $\begin{array}{c}n=74 \\
9.8 \pm 1.4\end{array}$ & $\begin{array}{c}n=78 \\
9.5 \pm 1.3\end{array}$ & $\begin{array}{c}n=70 \\
9.9 \pm 1.3\end{array}$ & 0.3 \\
\hline
\end{tabular}


shows participant flow during the study. There were no significant differences $(p>0.05)$ among groups over the course of the study (Table 1 ). Infants were held for $88 \%$ of vaccinations.

Infant Modified Behavioural Pain Scale scores obtained from the videotapes are shown in Table 2 . Baseline scores showed no evidence of an effect of treatment group $(p=0.4)$, but a significant effect of time (i.e., infant age) $(p<0.001)$. Needle scores showed group $(p=0.003)$ and time differences $(p<0.001)$. Scores were lower for the video-sucrose-lidocaine group compared with the control $(p<0.001)$, video $(p=0.003)$, and video-sucrose $(p=0.005)$ groups, respectively. There were no differences between any of the other groups. The mean ( \pm standard deviation [SD]) needle score was $6.3( \pm 0.8)$ in the video-sucrose-lidocaine group and $6.7( \pm 0.8)$ in each of the other 3 groups. The observed effect size (standardized mean difference [SMD]) was 0.5. Together, these results suggest the benefit derived from the lidocaine component of the regimen only. A post-hoc analysis accounting for sucrose and lidocaine implementation showed similar results. During the recovery phase, scores did not differ among groups ( $p=0.97)$, but did differ over time $(p<0.001)$.

Table 3 shows secondary pain outcomes. Physician numeric rating scale and observer Modified Behavioural Pain Scale scores differed among groups ( $p=0.020$ and $p=0.004$, respectively), with lower values for the video-sucrose-lidocaine group compared with the other groups and no other between-group differences. In addition, scores differed over time $(p<0.001)$. Parent numeric rating scale scores showed a time-group interaction (i.e., differences in group effects at different infant ages) ( $p=0.03)$. Cry duration and parent satisfaction scores did not differ among groups ( $p=0.05$ and 0.5 , respectively), but did differ over time $(p<0.001)$. There were no group differences for dichotomized pain scores $(p=0.2)$.

Transient skin reactions were common. The incidence of pallor differed among groups at 2 months $(p=0.01$ ) only (Table 4$)$.

\section{Interpretation}

Vaccination pain causes distress for infants and observers alike. ${ }^{3}$ Pain mitigation interventions are recommended to reduce suffering and prevent vaccine hesitancy. ${ }^{3-5}$ We found that, when used consistently during vaccine injections in the first year of life, only liposomal lidocaine combined with parental video instruction and orally administered sucrose showed a benefit on acute pain when compared with placebo, video alone, and video and sucrose together. We found no evidence of a benefit of any regimen during the recovery phase. In addition, large differences were seen in infant pain responses over time, with scores decreasing over the first 6 months of life, then increasing at 12 months.

The finding of a benefit of topically applied anesthetic for reducing infant vaccination pain is consistent with a recent systematic review. ${ }^{21}$ The observed effect size (SMD between groups), however, was lower in the present study (0.5 v. 0.9). Design features such as concomitant use of cointerventions (e.g., order of injection, no aspiration) and longitudinal approach may partially

\section{Table 2: Modified Behavioural Pain Scale scores during 2-, 4-, 6- and 12-month vaccinations}

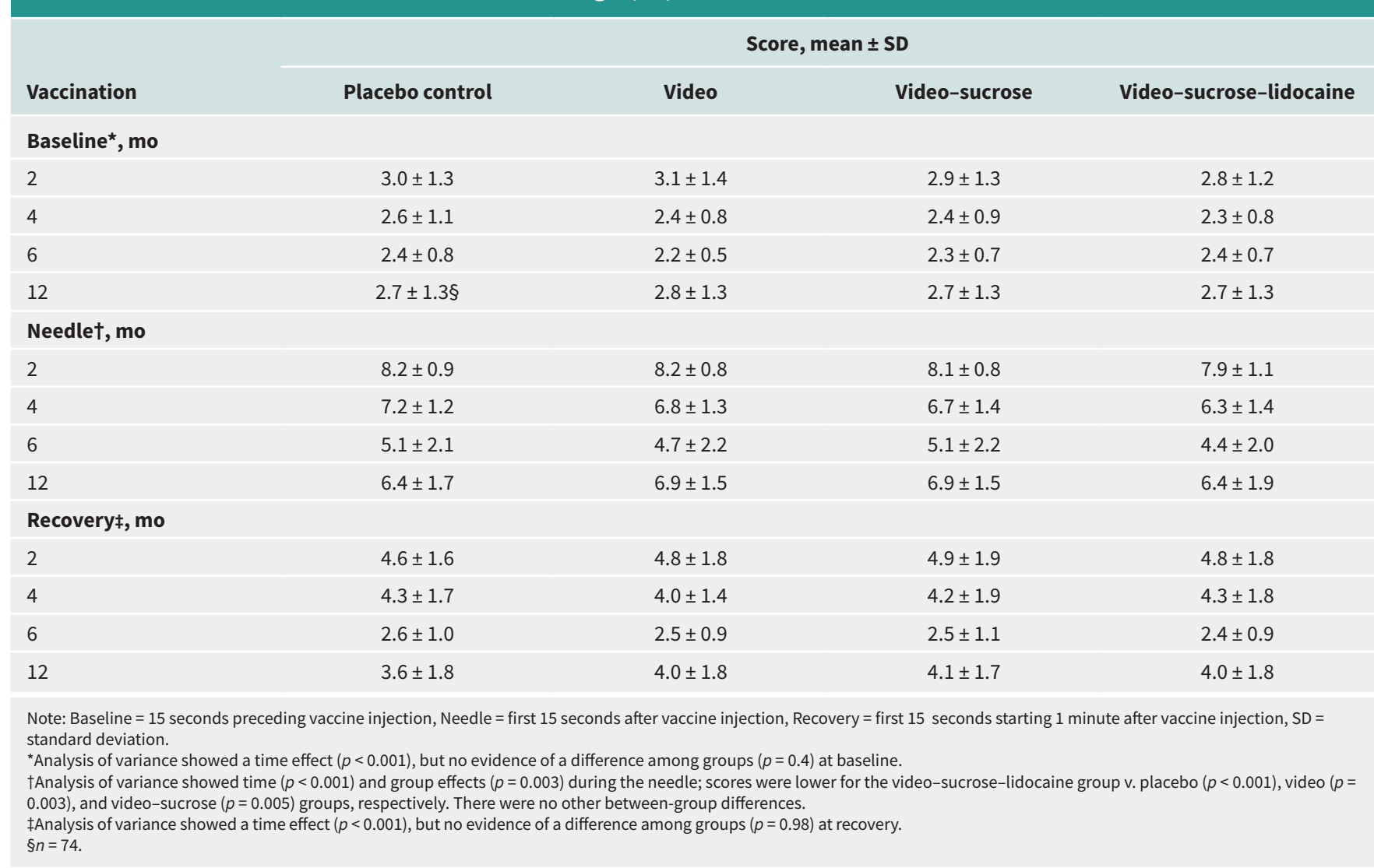


account for this difference. Evidence for the feasibility of topical anesthetics has been shown in previous studies that evaluated usual clinic waiting times ${ }^{22}$ and parental willingness to pay., Although not a stated objective of the present study, the success of the protocol across different practice settings supports the feasibility of all of the interventions examined.

The lack of benefit of both parental education and sucrose is somewhat inconsistent with previous studies. ${ }^{6,15}$ It is possible that the size of benefit conferred by these interventions may not have been sufficient over the cointerventions used, including holding by parents, which was highly prevalent in both active and placebo video groups. With respect to the apparent ineffectiveness of parental education specifically, it is possible that variability in how parents implemented suggested interventions (intensity, timing and duration) was high. Coaching by clinicians or more directive and age-specific guidance might have improved fidelity of implementation and resulted in observable benefit. However, the video was designed to be brief and to serve as a stand-alone intervention that could be implemented in any setting without additional resources. In addition, the control group video may have had

Table 3: Secondary pain outcomes during 2-, 4-, 6- and 12-month vaccinations

\begin{tabular}{|c|c|c|c|c|}
\hline \multirow[b]{2}{*}{ Characteristic } & \multicolumn{4}{|c|}{ Mean \pm SD* $^{*}$} \\
\hline & $\begin{array}{l}\text { Placebo control } \\
\quad n=88\end{array}$ & $\begin{array}{l}\text { Video } \\
n=88\end{array}$ & $\begin{array}{l}\text { Video-sucrose } \\
\quad n=87\end{array}$ & $\begin{array}{l}\text { Video-sucrose-lidocaine } \\
\qquad n=87\end{array}$ \\
\hline \multicolumn{5}{|l|}{ At 2 mo } \\
\hline Parent numeric rating scale $\dagger$ & $7.1 \pm 1.9$ & $7.3 \pm 2.1$ & $7.0 \pm 2.0$ & $6.4 \pm 2.3$ \\
\hline Physician numeric rating scale $\ddagger$ & $6.1 \pm 1.7$ & $6.3 \pm 1.7$ & $6.0 \pm 1.6$ & $5.5 \pm 2.0$ \\
\hline Observer Modified Behavioural Pain scaleł & $8.1 \pm 1.2$ & $8.3 \pm 1.1$ & $8.0 \pm 1.3$ & $7.7 \pm 1.3$ \\
\hline Cry duration, s§ & $23.2 \pm 6.1$ & $22.9 \pm 5.9$ & $22.5 \pm 6.1$ & $21.4 \pm 6.9$ \\
\hline No pain, no. (\%)ฯ & $0(0)$ & $0(0)$ & $0(0)$ & $0(0)$ \\
\hline Parent satisfaction§ & $3.7 \pm 1.1$ & $3.9 \pm 1.0$ & $3.8 \pm 1.0$ & $3.9 \pm 1.1$ \\
\hline At 4 mo & $n=82$ & $n=78$ & $n=78$ & $n=76$ \\
\hline Parent numeric rating scale $\dagger$ & $5.6 \pm 2.0$ & $5.2 \pm 2.2$ & $4.8 \pm 2.5$ & $4.3 \pm 2.1$ \\
\hline Physician numeric rating scale $\ddagger$ & $7.3 \pm 2.5$ & $4.5 \pm 2.0$ & $4.5 \pm 2.1$ & $4.0 \pm 1.9$ \\
\hline Observer Modified Behavioural Pain Scaleł & $5.1 \pm 1.9$ & $6.9 \pm 1.5$ & $6.8 \pm 1.6$ & $6.4 \pm 1.5$ \\
\hline Cry duration, s§ & $18.1 \pm 7.4$ & $16.0 \pm 7.5$ & $15.3 \pm 8.1$ & $14.4 \pm 7.0$ \\
\hline No pain, no. (\%)ฯ & $0(0)$ & $0(0)$ & $0(0)$ & $0(0)$ \\
\hline Parent satisfaction§ & $4.2 \pm 0.9$ & $4.3 \pm 1.0$ & $4.3 \pm 0.9$ & $4.5 \pm 0.9$ \\
\hline At 6 mo & $n=81$ & $n=75$ & $n=79$ & $n=74$ \\
\hline Parent numeric rating scale $\dagger$ & $2.6 \pm 2.7$ & $2.2 \pm 2.6$ & $3.1 \pm 2.6$ & $1.8 \pm 2.4$ \\
\hline Physician numeric rating scale $\ddagger$ & $2.1 \pm 2.2$ & $1.9 \pm 2.0$ & $2.3 \pm 2.2$ & $1.8 \pm 2.5$ \\
\hline Observer Modified Behavioural Pain Scaleł & $5.1 \pm 2.3$ & $4.5 \pm 2.0$ & $5.2 \pm 2.2$ & $4.4 \pm 2.2$ \\
\hline Cry duration, s§ & $7.9 \pm 9.5$ & $6.0 \pm 8.4$ & $7.8 \pm 8.7$ & $6.0 \pm 9.7$ \\
\hline No pain, no. (\%)ฯ & $14(17.3)$ & $19(25.3)$ & $15(19.0)$ & $22(29.7)$ \\
\hline Parent satisfaction§ & $4.7 \pm 0.6$ & $4.7 \pm 0.7$ & $4.7 \pm 0.8$ & $4.7 \pm 0.7$ \\
\hline At $12 \mathrm{mo}$ & $n=76$ & $n=75$ & $n=77$ & $n=71$ \\
\hline Parent numeric rating scale $\dagger$ & $4.8 \pm 2.7$ & $5.4 \pm 2.9$ & $5.5 \pm 2.7$ & $4.8 \pm 3.0$ \\
\hline Physician numeric rating scale $\ddagger$ & $4.4 \pm 2.3$ & $4.9 \pm 2.3$ & $4.9 \pm 2.3$ & $4.2 \pm 2.5$ \\
\hline Observer Modified Behavioural Pain Scaleł & $6.8 \pm 2.0$ & $7.0 \pm 1.9$ & $7.1 \pm 2.0$ & $6.6 \pm 2.2$ \\
\hline Cry duration, s§ & $18.3 \pm 10.0$ & $19.3 \pm 10.2$ & $19.9 \pm 9.8$ & $17.3 \pm 10.8$ \\
\hline No pain, no. (\%)ฯ & $0(0)$ & $1(1.3)$ & $0(0)$ & $0(0)$ \\
\hline Parent satisfaction§ & $4.2 \pm 1.1$ & $4.1 \pm 1.2$ & $4.1 \pm 1.0$ & $4.3 \pm 1.0$ \\
\hline \multicolumn{5}{|c|}{ 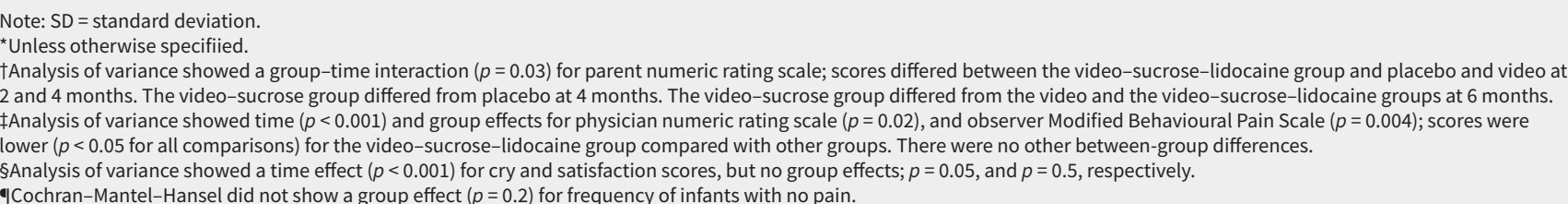 } \\
\hline
\end{tabular}


some therapeutic value despite it containing nonspecific information. We used the placebo video to facilitate blinding and serve as a time-matched activity for parents. Finally, the video and sucrose were embedded within a complex protocol (double-dummy design) that may have increased parental stress, which thereby reduced their abilities to optimally soothe their infants. It is unclear whether this is a substantial factor, given that parents routinely watch videos in clinics and rotavirus vaccine is given orally to young infants. In addition, relatively few parents withdrew due to study-specific concerns.

In regards to sucrose, it is possible that a subtherapeutic concentration contributed to the observed lack of benefit. In a recent meta-analysis, we showed a dose-response effect with a consistent benefit observed for strengths of $50 \%-75 \%$, whereas mixed results were seen for strengths between $20 \%$ and 33\%. ${ }^{21}$ The strength used in the present study (24\%) may have been insufficient to reliably confer a benefit. In addition, it is possible the effectiveness of sucrose wanes after the neonatal period. ${ }^{23}$ Because orally administered rotavirus vaccine contains sucrose in variable concentrations, including as high as $75 \%$ in some commercial formulations, and is routinely given to 2- and 4-month-old infants, its administration should precede injectable vaccines for the potential added benefit of pain relief. ${ }^{24}$ The present study suggests exogenous sucrose may not be warranted.

We hypothesize that at least 2 factors account for the variation in infant pain scores over time: painfulness of vaccine regimens given at each time ${ }^{17,25}$ and infant developmental factors. ${ }^{2,26,27}$

The observed treatment effect may not be sufficient to compel clinicians to change their practice, particularly due to the short duration of the pain felt. It is important to note, however, that pain relief is part of good vaccination practice. ${ }^{4} \mathrm{~A}$ short duration of iatrogenic pain does not justify not treating it. Brief epi- sodes of untreated iatrogenic pain can have long-term consequences, including future noncompliance with vaccination..$^{3,5}$

\section{Limitations}

There was a lack of strict control regarding the timing of study procedures because the study was integrated within clinical practices. This may have increased the variability and reduced our ability to detect differences among groups. In addition, we did not include breast feeding, even though it has proven pain-relieving effects. ${ }^{6}$ We excluded breast feeding because fidelity was expected to be poor over time owing to low breast-feeding rates. ${ }^{28}$

Our study had several strengths. First, the double-dummy design and blinding of outcome assessors minimized performance and detection bias. Second, inclusion of a large and diverse infant population from numerous practices and incorporating study procedures within regular clinic activities improved generalizability. Third, the 4-group longitudinal design allowed for a comprehensive evaluation. Finally, including multiple outcomes with similar results improves confidence in the findings.

\section{Conclusion}

Liposomal lidocaine reduced pain in infants undergoing vaccination when combined with parent video instruction and orally administered sucrose. There was no effect of either parent video instruction alone or parent video instruction and sucrose together.

The observed treatment effect, albeit above the a priori threshold value set for clinical significance, may not be sufficiently compelling to clinicians to alter clinical practice, particularly in light of the short-lived nature of the pain.Given that vaccination pain is iatrogenic and most infants were distressed despite the use of cointerventions, consideration should be given to adding lidocaine to reduce the burden of pain.

Table 4: Transient skin reactions

\begin{tabular}{|c|c|c|c|c|c|}
\hline Characteristic & $\begin{array}{l}\text { Placebo control } \\
\qquad n=88\end{array}$ & $\begin{array}{l}\text { Video } \\
n=88\end{array}$ & $\begin{array}{c}\text { Video-sucrose } \\
\quad n=87\end{array}$ & $\begin{array}{l}\text { Video-sucrose-lidocaine } \\
\qquad n=86\end{array}$ & $p$ value ${ }^{\star}$ \\
\hline \multicolumn{6}{|l|}{ At 2 mo } \\
\hline Pallor & $46(52.3)$ & $43(48.9)$ & $51(58.6)$ & $61(71.8) \dagger$ & 0.01 \\
\hline Redness & $62(70.4)$ & $57(64.8)$ & $62(71.3)$ & $69(80.2)$ & 0.2 \\
\hline At $4 \mathrm{mo}$ & $n=82$ & $n=78$ & $n=77$ & $n=76$ & \\
\hline Pallor & 29 (35.4) & 34 (43.6) & $36(46.7)$ & 39 (51.3) & 0.2 \\
\hline Redness & 48 (58.5) & 48 (61.5) & $48(62.3)$ & $51(67.1)$ & 0.7 \\
\hline At $6 \mathrm{mo}$ & $n=81$ & $n=75$ & $n=79$ & $n=74$ & \\
\hline Pallor & $26(32.1)$ & $27(36.0)$ & $28(35.4)$ & $38(51.4)$ & 0.07 \\
\hline Redness & $45(56.0)$ & $44(58.7)$ & 47 (59.5) & $47(63.5)$ & 0.8 \\
\hline At $12 \mathrm{mo}$ & $n=76$ & $n=75$ & $n=77$ & $n=71$ & \\
\hline Pallor & $31(40.8)$ & $35(46.7)$ & 40 (51.9) & $33(46.5)$ & 0.6 \\
\hline Redness & $50(65.8)$ & $48(64.0)$ & $53(68.8)$ & $53(74.6)$ & 0.5 \\
\hline
\end{tabular}


In light of these results, research is strongly recommended that explores less painful vaccine formulations and administration techniques. ${ }^{29}$ The effects of consistent pain management on the development of preprocedural anxiety (fear), hypersensitivity to pain and compliance with future vaccination warrant future investigation.

\section{References}

1. Jacobson RM, Swan A, Adegbenro A, et al.; Vaccine Research Group. Making vaccines more acceptable - methods to prevent and minimize pain and other common adverse events associated with vaccines. Vaccine 2001;19:2418-27.

2. Pillai Riddell R, Flora DB, Stevens SA, et al. Variability in infant acute pain responding meaningfully obscured by averaging pain responses. Pain 2013;154:714-21.

3. Taddio A, Chambers CT, Halperin SA, et al. Inadequate pain management during childhood immunization: the nerve of it. Clin Ther 2009;31(Suppl 2):S152-67.

4. Reducing pain at the time of vaccination: WHO position paper - September 2015. Wkly Epidemiol Rec 2015;90:505-10.

5. MacDonald NE; SAGE Working Group on Vaccine Hesitancy. Vaccine hesitancy: definition, scope and determinants. Vaccine 2015;33:4161-4.

6. Taddio A, McMurtry CM, Shah V, et al; HELPinKids\&Adults. Reducing pain during vaccine injections: clinical practice guideline. CMAJ 2015;187:975-82.

7. Taddio A, Appleton M, Bortolussi B, et al. Reducing the pain of childhood vaccination: an evidence-based clinical practice guideline. CMAJ 2010;182:E843-55.

8. Taddio A, Manley J, Potash L, et al. Routine immunization practices: use of topical anesthetics and oral analgesics. Pediatrics 2007;120:e637-43.

9. Taddio A, Ipp M, Thivakaran S, et al. Survey of the prevalence of immunization noncompliance due to needle fears in children and adults. Vaccine 2012;30:4807-12.

10. Harrison D, Sonja Elia S, Royle J, et al. Pain management strategies used during early childhood immunisation in Victoria. J Paediatr Child Health 2013;49:313-8.

11. Pillai Riddell RR, Racine NM, Gennis HG, et al. Non-pharmacological management of infant and young child procedural pain. Cochrane Database Syst Rev 2015;(12):CD006275.

12. Horton R, Pillai Riddell R, Moran G, et al. Do infant behaviors following immunization predict attachment? An exploratory study. Attach Hum Dev 2016;18:90-9.

13. Lisi D, Campbell L, Pillai Riddell R, et al. Naturalistic parental pain management during immunizations over the first year of life: observational norms from the OUCH cohort. Pain 2013;154:1245-53.

14. Hillgrove-Stuart J, Pillai Riddell R, Flora DB, et al. Caregiver soothing behaviors after immunization and infant attachment: a longitudinal analysis. J Dev Behav Pediatr 2015;36:681-9.
15. Pillai Riddell R, O'Neill M, Campbell L, et al. The ABCD's of pain management: a randomized controlled trial for a brief educational video for parents of infants undergoing vaccination [abstract]. Canadian Pain Society annual meeting; 2016 May 24-27; Vancouver.

16. Taddio A, Nulman I, Koren BS, et al. A revised measure of acute pain in infants. J Pain Symptom Manage 1995;10:456-63.

17. Ipp M, Parkin PC, Lear N, et al. Order of vaccine injection determines infant pain response. Arch Pediatr Adolesc Med 2009;163:469-72.

18. Taddio A, McMurtry CM, Shah V, et al. Methodology for knowledge synthesis of the management of vaccination pain and needle fear. Clin J Pain 2015; 31:S12-9.

19. Shah V, Taddio A, Rieder MJ. HELPinKIDS Team. Effectiveness and tolerability of pharmacological and combined interventions for reducing injection pain during routine childhood immunizations: systematic review and meta-analyses. Clin Ther 2009;31(Suppl 2):S104-51.

20. Hintze J. 2007. GESS User's Guide I: Quick start, introduction, importing microarray data, data utilities, and graphics. Kaysville (UT): NCSS; 2007.

21. Shah V, Taddio A, McMurtry CM, et al. HELPinKIDS Team. Pharmacological and combined interventions to reduce vaccine injection pain in children and adults: systematic review and meta-analysis. Clin J Pain 2015;31:S38-63.

22. Taddio A, Hogan ME, Gerges S, et al. Addressing parental concerns about pain during childhood vaccination: is there enough time to include pain management in the ambulatory setting? Clin J Pain 2012;28:238-42.

23. Harrison D, Yamada J, Adams-Webber T, et al. Sweet tasting solutions for reduction of needle-related procedural pain in children aged one to 16 years. Cochrane Database Syst Rev 2011;(10):CD008408.

24. Taddio A, Flanders D, Weinberg E, et al. A randomized trial of rotavirus vaccine versus sucrose solution for vaccine injection pain. Vaccine 2015;33:2939-43.

25. Ipp M, Cohen E, Goldbach M, et al. Effect of choice of measles-mumps-rubella vaccine on immediate vaccination pain in infants. Arch Pediatr Adolesc Med 2004;158:323-6.

26. Ipp M, Taddio A, Goldbach M, et al. Effects of age, gender and holding on pain response during infant immunization. Can J Clin Pharmacol 2004;11:e2-7.

27. Brooker RJ, Buss KA, Lemery-Chalfant K, et al. The development of stranger fear in infancy and toddlerhood: normative development, individual differences, antecedents, and outcomes. Dev Sci 2013;16:864-78.

28. Haiek LN, Gauthier DL, Brosseau D, et al. Understanding breastfeeding behavior: rates and shifts in patterns in Québec. J Hum Lact 2007;23:24-31.

29. Williams D. Vaccines: the best medicine - 2014 annual report of the Chief Medical Officer of Health of Ontario to the Legislative Assembly of Ontario. Available: www.health.gov.on.ca/en/common/ministry/publications/reports/cmoh_14_ vaccines/docs/cmoh_14_vaccines.pdf (accessed 2016 Apr. 30).
Competing interests: Anna Taddio declares a research grant from Pfizer, and study supplies from Natus and Ferndale. The other authors declare no conflicts of interest.

This article has been peer reviewed.

Affiliations: Leslie Dan Faculty of Pharmacy (Taddio, Fletcher, Wong, McNair, Mithal), University of Toronto; Child Health Evaluative Sciences (Taddio), The Hospital for Sick Children, Toronto, Ont.; Department of Psychology (Pillai Riddell), York University, North York, Ont.; Department of Psychiatry (Pillai Riddell) and Paediatrics (Ipp), University of Toronto, Toronto, Ont.; Pediatricians (Moss, Baker, Tolkin, Malini, Feerasta, Govan), North York, Ont.; Biostatistics and Data Analysis Unit (Stephens), The Hospital for Sick Children, Toronto, Ont.
Contributors: Anna Taddio, Rebecca Pillai Riddell, Moshe Ipp and Derek Stephens contributed to the conception and design of the study and the analysis of the data. Moshe Ipp, Steven Moss, Stephen Baker, Jonathan Tolkin, Dave Malini, Sharmeen Feeresta, Preeya Govan, Emma Fletcher, Horace Wong, Caitlin McNair and Priyanjali Mithal contributed to the acquisition interpretation of the data. Anna Taddio wrote the first draft of the article. All of the authors revised the manuscript critically for important intellectual content, gave final approval of the version to be published and agreed to act as guarantors of the work.
Funding: External funding was acquired by Anna Taddio from Pfizer via the Investigator Initiated Research program. The funding agency did not have any input into the study.

Acknowledgements: Study supplies (placebo and active) were supplied by Ferndale and Natus. The study video was produced in collaboration with www.aboutkidshealth.ca.

Accepted: Aug. 22, 2016

Early release: Dec. 12, 2016

Correspondence to: Anna Taddio, anna.taddio@utoronto.ca 